This is the final peer-reviewed accepted manuscript of:

D. Rose et al., 'Behavioral Circumscription and the Folk Psychology of Belief: A Study in Ethno-Mentalizing', Thought 6, 2017, pp. 193-203.

The final published version is available online at:

https://doi.org/10.1002/tht3.248

Rights / License:

The terms and conditions for the reuse of this version of the manuscript are specified in the publishing policy. For all terms of use and more information see the publisher's website.

This item was downloaded from IRIS Università di Bologna (https://cris.unibo.it/)

When citing, please refer to the published version. 


\title{
Behavioral Circumscription and the Folk Psychology of Belief: A Study in Ethno-Mentalizing
}

\author{
David Rose ${ }^{1}$, Edouard Machery ${ }^{2}$, Stephen Stich $^{1}$, Mario Alai ${ }^{3}$, Adriano Angelucci ${ }^{3}$, Renata Berniūnas ${ }^{4}$, \\ Emma E. Buchtel ${ }^{5}$, Amita Chatterjee ${ }^{6}$, Hyundeuk Cheon ${ }^{7}$, In-Rae Cho ${ }^{8}$, Daniel Cohnitz ${ }^{9}$, Florian Cova ${ }^{10}$, \\ Vilius Dranseika ${ }^{4}$, Ángeles Eraña Lagos ${ }^{11}$, Laleh Ghadakpour ${ }^{12}$, Maurice Grinberg ${ }^{13}$, Ivar Hannikainen ${ }^{14}$, \\ Takaaki Hashimoto ${ }^{15}$, Amir Horowitz ${ }^{16}$, Evgeniya Hristova ${ }^{17}$, Yasmina Jraissati ${ }^{18}$, Veselina Kadreva ${ }^{17}$, Kaori \\ Karasawa $^{15}$, Hackjin Kim ${ }^{19}$, Yeonjeong Kim ${ }^{20}$, Minwoo Lee $^{19}$, Carlos Mauro ${ }^{21}$, Masaharu Mizumoto ${ }^{22}$, \\ Sebastiano Moruzzi ${ }^{23}$, Christopher Y. Olivola ${ }^{20}$, Jorge Ornelas ${ }^{24}$, Barbara Osimani ${ }^{25}$, Carlos Romero ${ }^{11}$, \\ Alejandro Rosas ${ }^{26}$, Massimo Sangoi ${ }^{3}$, Andrea Sereni ${ }^{27}$, Sarah Songhorian ${ }^{28}$, Paulo Sousa ${ }^{29}$, Noel Struchiner ${ }^{14}$, \\ Vera Tripodi ${ }^{30}$, Naoki Usui ${ }^{31}$, Alejandro Vázquez del Mercado ${ }^{11}$, Giorgio Volpe ${ }^{23}$, Hrag A. Vosgerichian ${ }^{18}$, \\ Xueyi Zhang ${ }^{32} \&$ Jing Zhu $^{33}$
}

\begin{abstract}
${ }^{1}$ Rutgers University; ${ }^{2}$ University of Pittsburgh; ${ }^{3}$ University of Urbino; ${ }^{4}$ Vilnius University; ${ }^{5}$ The Education University of Hong Kong; ${ }^{6}$ Jadavpur University; ${ }^{7}$ Ewha Womans University; ${ }^{8}$ Seoul National University; ${ }^{9}$ Utrecht University; ${ }^{10}$ University of Geneva; ${ }^{11}$ Instituto de Investigaciones Filosóficas, UNAM; ${ }^{12}$ Iran; ${ }^{13}$ New Bulgarian University; ${ }^{14}$ Pontifical Catholic University of Rio de Janeiro; ${ }^{15}$ University of Tokyo; ${ }^{16}$ Open University of Israel; 17 New Bulgarian University; ${ }^{18}$ American University of Beirut; ${ }^{19}$ Korea University; ${ }^{20}$ Carnegie Mellon University; ${ }^{21}$ Católica Porto Business School; ${ }^{22}$ Japan Advanced Institute of Science and Technology; ${ }^{23}$ University of Bologna; ${ }^{24}$ Universidad Autónoma de San Luis Potosí; ${ }^{25}$ Ludwig-Maximilians Univesität, München - MCMP; ${ }^{26}$ National University of Colombia; ${ }^{27}$ Scuola Universitaria Superiore IUSS Pavia; ${ }^{28}$ Università Vita-Salute San Raffaele Milano; ${ }^{29}$ Institute of Cognition and Culture, Queen's University Belfast; ${ }^{30}$ University of Turin; ${ }^{31}$ Mie University; ${ }^{32}$ Southeast University; ${ }^{33}$ Sun Yat-Sen University
\end{abstract}

\begin{abstract}
Is behavioral integration (i.e., which occurs when a subject's assertion that p matches her nonverbal behavior) a necessary feature of belief in folk psychology? Our data from over 5,000 people across 26 samples, spanning 22 countries suggests that it is not. Given the surprising cross-cultural robustness of our findings, we argue that the types of evidence for the ascription of a belief are, at least in some circumstances, lexicographically ordered: assertions are first taken into account, and when an agent sincerely asserts that $p$, nonlinguistic behavioral evidence is disregarded. In light of this, we take ourselves to have discovered a universal principle governing the ascription of beliefs in folk psychology.
\end{abstract}

Keywords: behavioral circumscription; folk psychology; belief; cross-cultural; delusion

In a well-known case of Capgras delusion, a patient asserts that his or her loved one has been replaced by an imposter, yet continues to eat, sleep, and live with the alleged imposter (e.g., Hirstein and Ramachandran 1997). This is a striking case of "behavioral circumscription": a subject's assertion that $p$ does not match her nonverbal behaviors. By contrast, what we will call "behavioral integration" occurs when a subject's assertion that $p$ matches her nonverbal behaviors. Many philosophers have maintained that lay people refrain from ascribing belief in cases of behavioral circumscription (e.g., Bayne 2010; Bortolotti 2012; Bortolotti and Mameli 2012; Egan 2009; Frankish 2012; Murphy 2012; Schwitzgebel 2001, 2010, 2012; Tumulty 2012). The severe behavioral circumscription present in typical cases of Capgras delusion suggests that the delusional attitude "fail[s] to play the functional role that is essential to a state's being a belief" (Bayne 2010, p. 330) and "the practice of belief ascription start[s] to break down" (Schwitzgebel 2012, p. 16).

Some have held that the relevant folk psychological attitude present in the Capgras-delusion and similar cases is imagination (e.g., Currie 2000; Currie and Jureidini 2001; Currie and Ravenscroft 2002). Others have held that no familiar folk psychological attitude captures the relevant attitude displayed in these cases and that we need some gerrymandered attitude, such as "bimagination", a mix of belief and imaginan tion, to capture the relevant attitude (Egan 2009). Still others have held that while severe behavioral circumscription counts against classifying the attitude displayed in these cases as belief, the attitude is nonetheless belief-like, perhaps an instance of "anomalous" belief, "in-between belief," or the like (e.g., Bortolotti 2012; Reimer 2010; Schwitzgebel 2012; Tumulty 2012). But while many philosophers hold that behavioral integration is necessary for the folk ascription of belief - and so behavioral circumscription undermines belief ascription- 
they have not offered any empirical evidence in support of this claim.

We doubt that behavioral circumscription undermines belief ascription in folk psychology. Our doubt is encouraged by the results reported in Rose, Buckwalter, and Turri (2014) who found that the folk overwhelmingly attribute belief in cases of Capgras delusion. This suggests that nonlinguistic behavior sometimes does not count as evidence for or against the possession of a belief. But why might nonlinguistic behavior fail to count as evidence for or against the possession of a belief? Our view is that nonlinguistic behavior sometimes does not count as evidence for or against the possession of a belief because the type of evidence that is required for the ascription of belief is lexicographically ordered: assertions are first taken into account, and when an agent sincerely asserts that $p$, nonlinguistic behavioral evidence is disregarded. If an agent does not make any assertion or if it is not clear whether her assertion is sincere, nonlinguistic behavioral evidence is taken into account. And so in what follows, we'll present evidence that across 22 countries and 17 languages behavioral circumscription does not undermine belief ascription in folk psychology.

\section{Method and participants}

We collected data from 5,788 people across 26 samples, spanning 22 countries. Each subject was randomly assigned to one of two conditions. They read one of two cases (we'll call them "Consistent" and "Inconsistent") based on Rose, Buckwalter, and Turri (2014):

Don and Katherine had been married for ten years. Like most married couples, they spent a lot of time together and did many things together. They regularly shared meals, went to themovies, lived in the same house, and slept in the same bed.Then one day, as Don was driving to the store, a car drove through a red light, hitting the driver side door of Don's car. Don suffered a traumatic brain injury as the result of the gruesome traffic accident.

In the year following his injury, Don began what appeared to be a remarkable and speedy recovery. He regained his powers of speech, and his intelligence, as well as nearly all his cognitive and social skills. However there was something very strange about Don after his accident: he would tell his friends, family and doctors that his wife, Katherine, had been replaced by an imposter.

Consistent: In addition, Don now always refused to eat meals with her, go to the movies with her, and sleep in the same bed with her. Katherine was very surprised and saddened by the things Don would say.

Inconsistent: Surprisingly, however, Don continued to always eat meals with her, go to the movies with her, live in the same house as her, and sleep in the same bed with her. Katherine was very surprised and saddened by the things Don would say.

After reading one of these two cases, participants answered a comprehension question, followed by a question about what Don believes about his wife:

Comprehension: According to the story, which of the following statements is correct? [Don tells his friends that his parents have been replaced by imposters/Don tells his friends that his wife has been replaced by an imposter.]

Belief: Which option best reflects your personal opinion on the matter? [Don believes that Katherine is an imposter/Don does not believe that Katherine is an imposter.]

The cases were translated into 17 languages and presented in the respective native language for each group (see Supplementary Materials). ${ }^{1}$

\section{Results}

234 people answered Comprehension incorrectly. Demographics for the remaining participants are in Table 1.

Analyzing responses from the remaining 5,554 participants, we found a small effect of behavioral circumscription on belief ascription, $\chi^{2}(1,5554)=128.675, p<.001$, Cramer's $V=.152$, with the vast 
Table 1 Denographic Information About theStudy's Purticipunts Who Answerd Compuehensiou Correctly, Induding Couniries in Which Data Were Collected, Nature of the Sumple (Stadents vs Nonstudents), and Mode of Survey Administration (Puper-Pencil we Web-bued, Volunters w. L Exhunge of a Compensation, Lungudye of the Surncy)

\begin{tabular}{|c|c|c|c|c|c|}
\hline Coustry & Students? & Methad & Payment & Language & $N$ \\
\hline \multicolumn{6}{|l|}{ Europe } \\
\hline Bulguria & $\mathrm{N}$ & Wob-bused & Volunteers & Hulgarian & 403 \\
\hline France & $\mathbf{N}$ & Wob-bused & $\begin{array}{l}\text { Compensition } \& \\
\text { volunteers }\end{array}$ & Fresch & 429 \\
\hline Cermay & $\mathbf{N}$ & Web-bued & Compenution & Cierman & 209 \\
\hline Italy & $\mathrm{Y}$ & Paper-pendl & Voluniters & Italian & 198 \\
\hline Lithuania & $\mathbf{N}$ & Paper-pendl & Volunteers & Lithuanian & 205 \\
\hline Lithuania & $\mathrm{Y}$ & Piper-pendl & Volunteers & Lithuanian & 146 \\
\hline Portugal & $\mathrm{Y}$ & Piper-pendl & Volunteers & Portuguese & 1 B. \\
\hline Spain & $\mathbf{N}$ & Wob-bused & Compensation & Spaninh & 271 \\
\hline Switerland & $\mathbf{N}$ & $\begin{array}{l}\text { Puper-pendl is } \\
\text { web-bued }\end{array}$ & Vhlunters & Fresch & 50 \\
\hline Switerland & $\mathrm{I}$ & $\begin{array}{l}\text { Paper-pendl s } \\
\text { web-based }\end{array}$ & $\begin{array}{l}\text { Compencition } d \\
\text { volunters }\end{array}$ & Fresch & 26 \\
\hline $\begin{array}{l}\text { UK } \\
\text { Middle East }\end{array}$ & $\mathbf{N}$ & Wob-bused & Compensition & English & 266 \\
\hline Inan & $\mathbf{N}$ & Paper-pendl & Volunteers & Persian & 200 \\
\hline lsrad & $\mathrm{Y}$ & Wob-bued & Voluntears & Hebrew & 179 \\
\hline Bedouin & $\mathbf{N}$ & Paper-pendl & Volunteers & Arabic & 50 \\
\hline $\begin{array}{l}\text { Lebanson } \\
\text { Centril } 8 \text { Y }\end{array}$ & \multicolumn{2}{|c|}{ Central \& North } & Volunteers & Englikh & 164 \\
\hline America & & & & & \\
\hline Mexico & $\mathbb{N}$ & Puper-pendl & Volunteers & Spanish & 181 \\
\hline $\begin{array}{l}\text { USA } \\
\text { South Ameri }\end{array}$ & $\mathbf{N}$ & Web-bued & Compenation & Enylikh & 248 \\
\hline Braxil & $\mathrm{Y}$ & Paper-pendl & Volunteers & Portuguese & 160 \\
\hline \multicolumn{5}{|l|}{ Eust Asia } & 135 \\
\hline China & $\mathrm{Y}$ & Puper-pendl & Voluntetrs & $\begin{array}{l}\text { Chinese, } \\
\text { Truditional }\end{array}$ & 181 \\
\hline China & $\mathrm{Y}$ & Paper-pendl & Volunteers & $\begin{array}{l}\text { Chinese, } \\
\text { Simplified }\end{array}$ & 164 \\
\hline China & $\mathbf{N}$ & Wob-bused & Compenution & Chinese, & 215 \\
\hline Hong Kong & $\mathrm{Y}$ & Web-bused & Compenution & $\begin{array}{l}\text { Simplified } \\
\text { Chinese, } \\
\text { Truditional }\end{array}$ & 142 \\
\hline |rpun & $\mathbf{N}$ & Wob-based & Compenution & Japunese & 182 \\
\hline Japun & $\mathrm{Y}$ & Paper-pendl & Wolunteers & Japunese & $20 \mathrm{~s}$ \\
\hline South Korea & $\mathrm{N}$ & Wob-bued & Compersation & Kortan & 170 \\
\hline Mongpolia & $\mathrm{Y}$ & Paper-pandl & Vobunters & Mangolian & 170 \\
\hline \multicolumn{6}{|c|}{$\begin{array}{l}\text { South } B \text { southeast } \\
\text { Ala }\end{array}$} \\
\hline Indocesia & $\mathrm{Y}$ & Paper-pendl & Compensation & Indonesian & 189 \\
\hline India & $\mathrm{Y}$ & Paper-pendl & Volunteers & Bengali & 184 \\
\hline
\end{tabular}




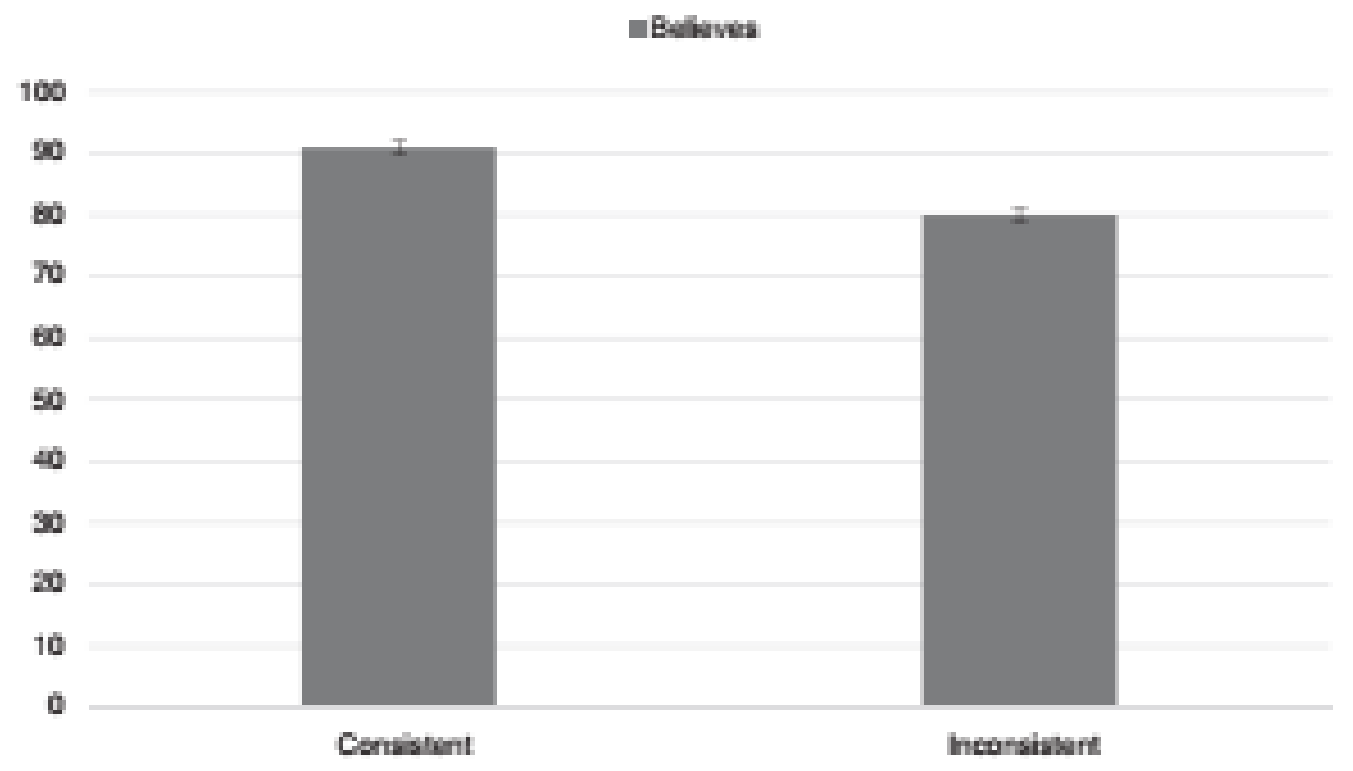

Fhure 1: Overall belief acription in the consistent and inounsteat cass with $95 \%$ confidenoe intervals.

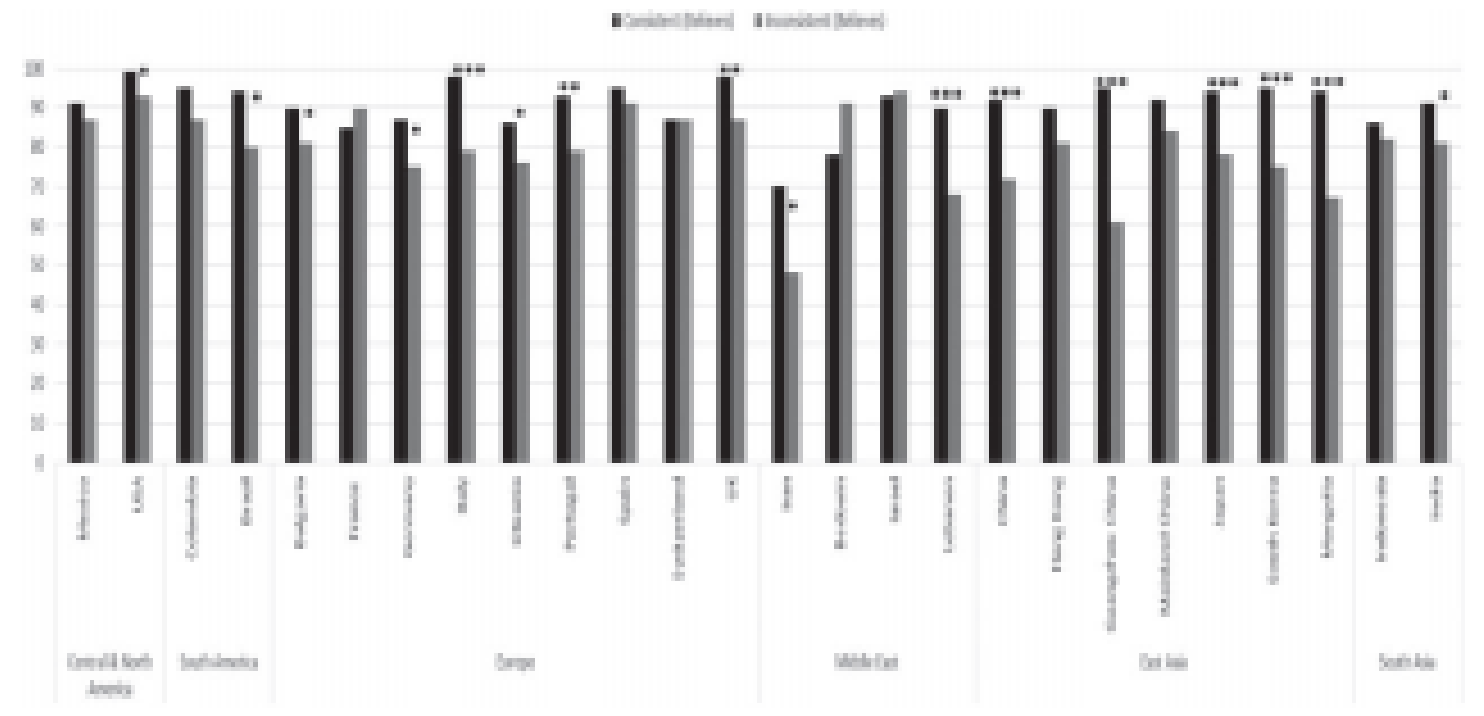

Fhure 2: Rates of belief ascription for consktent and incousistent care for each site (Pp a .05,

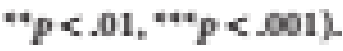

majority of individuals ascribing belief (91\% in Consistent, $80 \%$ in Inconsistent) despite severe behavioral circumscription see Figure 1). ${ }^{2}$

We then analyzed the effect of behavioral circumscription on belief ascription within each site. The results are depicted in Figure 2 (see also Table 1 in Supplementary Materials).

In brief, we found that in all sites (except Iran and Guangzhou China) rates of belief ascription significantly exceeded chance (50\%) even when nonlinguistic behavior is at odds with a speaker's assertion (Table 2). 
Table 2 Test of Belief Attribution Against Chance (50\%) in Both Consistent and Inconsistent Cases for Each Site

\begin{tabular}{|c|c|c|}
\hline Sample & $\begin{array}{l}\text { Consistent } \\
\left(\chi^{2}\right)(p \text {-value })\end{array}$ & $\begin{array}{l}\text { Inconsistent } \\
\left(\chi^{2}\right)(p \text {-value })\end{array}$ \\
\hline \multicolumn{3}{|c|}{ Central and North America } \\
\hline Mexico & $53.481^{* * *}$ & $56.627^{* * *}$ \\
\hline USA & $120.032 * * *$ & $90.613^{* * * *}$ \\
\hline \multicolumn{3}{|l|}{ South America } \\
\hline Colombia & $59.853^{* * *}$ & $32.267^{* * *}$ \\
\hline Brazil & $65.120^{* * *}$ & $28.800^{* * * *}$ \\
\hline \multicolumn{3}{|l|}{ Europe } \\
\hline Bulgaria & $115.200^{* * *}$ & $84.166^{* * *}$ \\
\hline France & $105.140^{* * *}$ & $139.205^{* * *}$ \\
\hline Germany & $59.259 * * *$ & $25.752^{* * *}$ \\
\hline Italy & $91.162^{* * *}$ & $32.818^{* * *}$ \\
\hline Lithuania & $91.124^{* * *}$ & $46.522 * * *$ \\
\hline Portugal & $66.618^{* * *}$ & $31.696^{* * *}$ \\
\hline Spain & $113.400^{* * *}$ & $87.397^{* * *}$ \\
\hline Switzerland & $17.065^{* * *}$ & $24.200^{* * * *}$ \\
\hline UK & $120.273^{* * *}$ & $71.672^{* * *}$ \\
\hline \multicolumn{3}{|l|}{ Middle East } \\
\hline Iran & $16.000^{* * * *}$ & .160 .689 \\
\hline Bedouin & $8.333^{* *}$ & $15.969 * * *$ \\
\hline Israel & $58.778 * * *$ & $75.469 * * *$ \\
\hline Lebanon & $54.084^{* * *}$ & $10.383^{* *}$ \\
\hline \multicolumn{3}{|l|}{ East Asia } \\
\hline China & $60.297^{* * *}$ & $17.695^{* * *}$ \\
\hline Hong Kong & $62.082^{* * * *}$ & $35.787^{* * *}$ \\
\hline Guangzhou China & $74.075^{* * *}$ & 3.169 .075 \\
\hline Mainland China & $75.872^{* * *}$ & $48.906 * * *$ \\
\hline Japan & $140.247^{* * *}$ & $66.305^{* * *}$ \\
\hline South Korea & $66.780^{* * *}$ & $22.000^{* * * *}$ \\
\hline Mongolia & $65.190^{* * *}$ & $10.465^{* *}$ \\
\hline \multicolumn{3}{|l|}{ South Asia } \\
\hline Indonesia & $48.269 * * *$ & $40.042^{* * *}$ \\
\hline India & $61.813^{* * * *}$ & $34.935^{* * *}$ \\
\hline
\end{tabular}

${ }^{*} p<.05,{ }^{* *} p<.01,{ }^{* * *} p<.001$.

Participants sampled from Iran attributed belief less frequently in both the consistent and inconsistent cases. While the majority attributed belief in the consistent case, people were divided in the inconsistent case. A somewhat similar pattern occurred with participants sampled from Guangzhou China, though the majority in the inconsistent case attributed belief at rates that marginally exceeded chance (see Table 2). The key point, however, for present purposes is this: their practice of belief attribution is not "breaking down" in the way we would expect if behavioral integration were a necessary feature of belief. They may be somewhat ambivalent, but they are clearly not denying belief in the way we would expect if behavioral integration was necessary for belief ascription in folk psychology.

\section{Discussion}

We have found that in many countries, across many languages, once a speaker has sincerely asserted that $p$, people do not refrain from ascribing belief when nonlinguistic behavior is at odds with the possession of a 
belief that $p$ : in fact, once a speaker sincerely asserts that $p$, nonlinguistic behavioral evidence seems to be largely disregarded. ${ }^{3}$ Our results dramatically extend the findings from Rose, Buckwalter, and Turri (2014) for USA participants.

Of course our results do not mean that nonlinguistic behavior never counts as evidence for or against the possession of a belief. When an agent does not assert anything, her behavior is often telling. What the data suggests is that the types of evidence for the ascription of a belief are, at least in some circumstances, lexicographically ordered: sincere assertions are first taken into account, and when an agent sincerely asserts that $p$, nonlinguistic behavioral evidence is disregarded. If an agent does not make any assertion, nonlinguistic behavioral evidence is then taken into account. (Various types of nonlinguistic behavioral evidence may also be lexicographically ordered, but our data does not speak to that question.)

We also find that rates of belief ascription are high across virtually every site despite severe behavioral circumscription. This is not at all what we would expect if behavioral integration was necessary for belief ascription in the folk psychology of belief. Sincere assertions and nonlinguistic behavior seem lexically ordered in the 22 sites we collected data from. Some of our data come from students, others from nonstudent populations. While most data sets come from industrialized societies, two data sets come from traditional societies: the Bedouin in Israel and the Nasa People of Colombia.

The upshot is that we may have discovered a universal principle of folk psychology that psychologists and philosophers of cognitive science working on mindreading have so far ignored: behavioral evidence and sincere assertions are lexicographically ordered. Naturally, further cross-cultural and cross-linguistic research is needed to further support this claim, but the scope of our enquiry provides strong support for our hypothesis about universality.

We did find that behavioral circumscription produced an effect in 16 of the $26(61.5 \%)$ sites examined (see Figure 2 and Supplementary Materials), but this effect is typically small: Of those 16 sites, 14 (87.5\%) displayed a small effect of behavioral circumscription on belief ascription (see Figures 3 and 4).

Participants sampled from Mongolia and from Guangzhou in China displayed a moderate effect of behavioral circumscription on belief ascription (a 27\% difference in Mongolia; a 34\% difference in Guangzhou), but the majority of participants in Mongolia attributed belief despite severe behavioral circumscription (see Table 2). Moreover, those in Guangzhou China attributed belief at rates that marginally exceeded chance in the inconsistent case (see Table 2). That said, it may be that a minority of varying size, depending perhaps on culture and language (see Figures 3 and 4), does not lexicographically order sincere assertion and nonlinguistic behavior to ascribe beliefs.

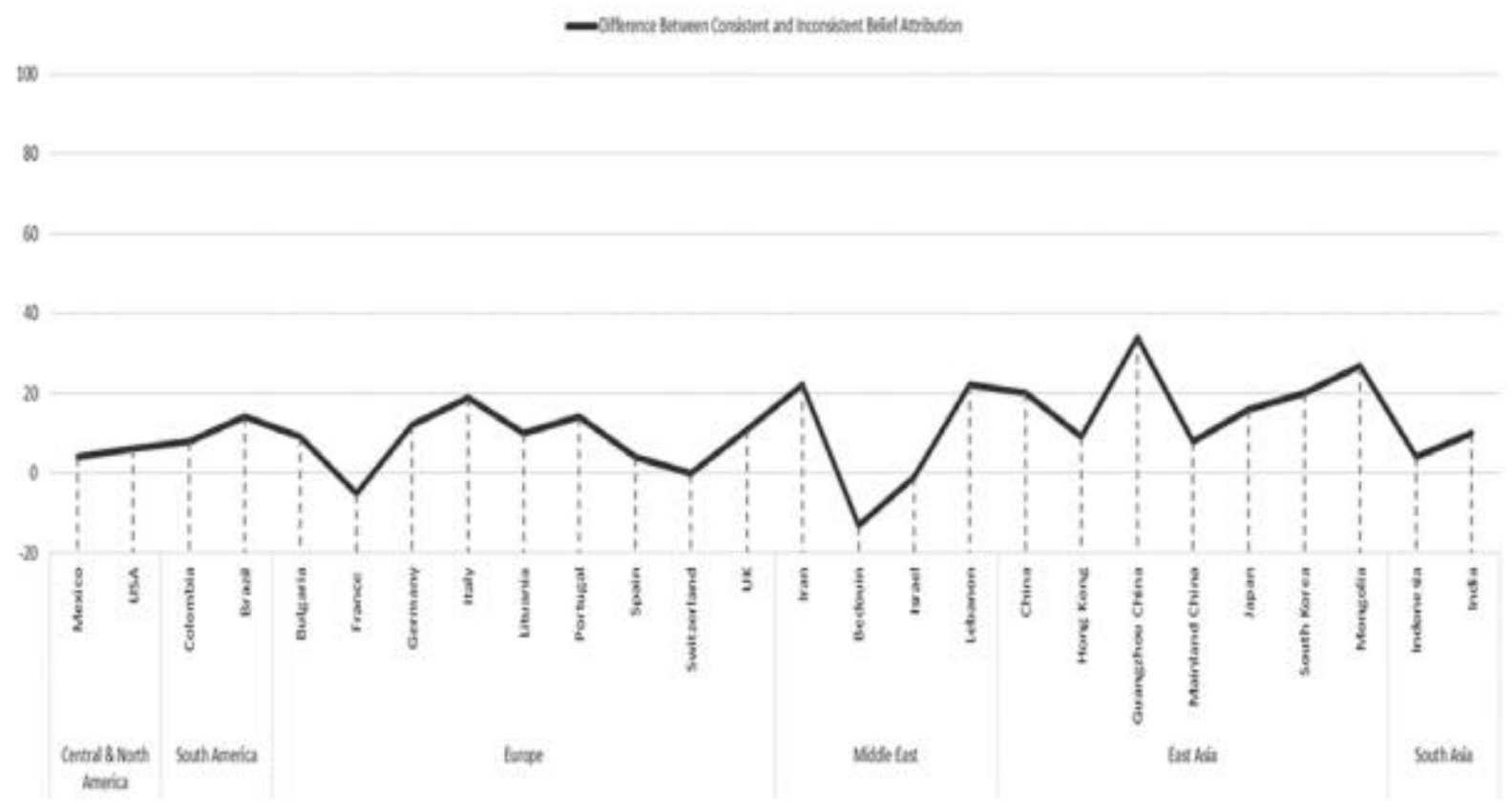

Figure 3: Difference in rates of belief attribution between consistent and inconsistent cases.

To conclude, taken together, our results suggest that behavioral integration is not a necessary feature of 
belief in folk psychology: people tend to ascribe beliefs when nonlinguistic behavior is at odds or in line with sincere assertions, though the rate does vary depending on the culture and language.

\section{Objections and responses}

\subsection{BELIEF is not a universal concept}

Proponents of Natural Semantic Metalanguage (NSM) have argued that in contrast to KNOW, BELIEF is not a universal concept, a "semantic prime" in their terminology (e.g., Wierzbicka 2006, Ch. 7). ${ }^{4}$ It cannot thus be that we have discovered a universal principle governing the ascription of beliefs in folk psychology.

The NSM claim that many languages lack a term for "belief" raises deep questions about synonymy and translation. If the NSM claim were true, then many of our translations would be defective. We are inclined to think that the NSM view on what is required for synonymy and translation is far too stringent. But this is not the place to defend that view. Instead, we can simply make clear that our claim is about standard translations, the sorts that are provided by dictionaries and expert translators. We maintain that behavioral integration is not necessary for belief attribution in English, nor is it necessary for the attribution of the standard translation of "belief" in a wide range of languages from quite different language groups. This is impressive evidence that the phenomenon is universal, though since there are about 6,000 extant languages, it is entirely possible that behavioral integration is necessary for the standard translation of "belief" in one or more of those languages.

Finally, we would add that even if the NSM claim is right, it is still the case that we have discovered a universal principle governing the ascription of beliefs in folk psychology where BELIEF is acquired.

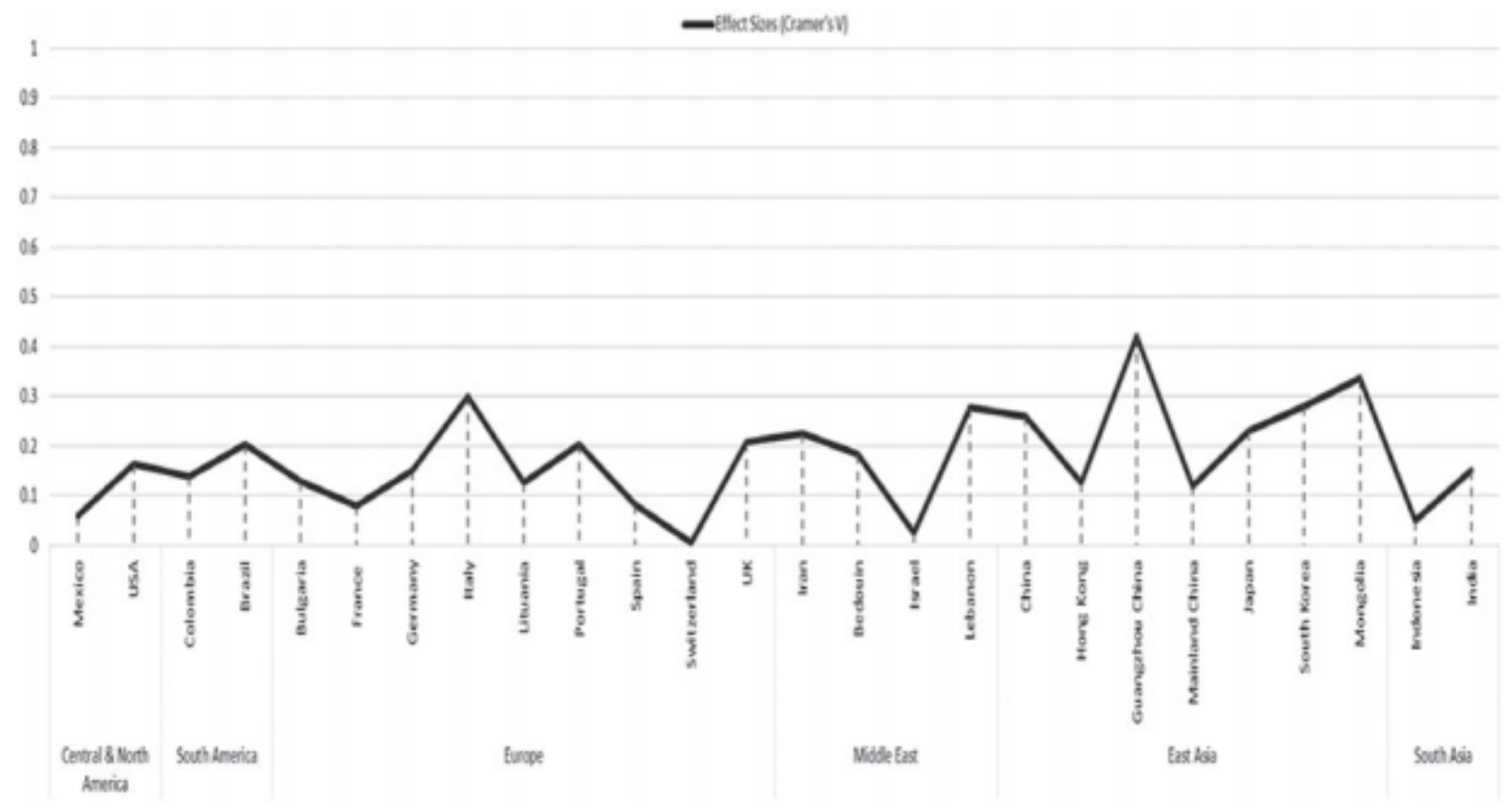

\section{Figure 4: Effect size (using Cramer's $V$ ) of behavioral circumscription on belief attribution for each site (See fn. 1 on benchmarks for interpreting Cramer's $V$.)}

\subsection{Limitations of the vignette}

One could object that our failure to find behavioral circumscription preventing belief ascription is simply due to the shortcomings of our vignette.

We concede that this is a possibility. However, to be in a position to take this objection seriously, we would need to know how exactly the vignette we used prevents the influence of behavioral circumscription on belief ascription to manifest itself. Furthermore, this vignette is based on cases extensively discussed in the philosophical literature on belief, namely, typical cases of Capgras delusion. 


\subsection{Sincerity}

One could challenge our conclusion that behavioral circumscription does not prevent belief ascription by insisting that when we decide whether someone makes a sincere assertion and thus believes what she seems to say, we do pay attention to how this person behaves. How could it be, then, that when behavior and speech conflict we simply overlook behavior?

We sometimes do pay attention to behavior to assess sincerity, but, first, we often do not need to appeal to nonlinguistic behavioral evidence to decide whether an assertion is sincere: For instance, we may be told that a speaker sincerely asserted that $p$ or the conversational context may imply that her assertion was sincere.

Second, the issue of interest among philosophers debating about belief ascription and the nature of belief is not whether we overlook behavior when it conflicts with speech in general. Rather, the issue of interest is whether people who sincerely assert that $p$ believe that $p$ even when their nonlinguistic behavior is at odds with believing that $p$. And in these cases, such as cases of Capgras delusion, the evidence does suggest that in folk psychology the kind of evidence required for the ascription of belief is lexicographically ordered.

\section{Conclusion}

Many philosophers hold that behavioral integration plays a necessary role in the folk psychology of belief. Our results suggest that this view is badly mistaken. Despite being confronted with a case involving severe behavioral circumscription - the case of Capgras delusion-people across a wide range of cultures and languages overwhelmingly attribute belief (in all but, at most, two sites examined out of 26 sites in 22 countries), and nowhere did we find a dramatic effect of behavioral circumscription on belief ascription. One key lesson then from these cross-cultural results is that it seems to be a cross-cultural folk-psychological universal that behavioral integration is not required for belief ascription.

What explains our results? We propose that sincere assertions and nonlinguistic behavior are lexicographically ordered: when a speaker sincerely asserts that $p$, we tend to ascribe to her the belief that $p$ whether or not her nonlinguistic behavior reflects that belief. Our cross-cultural and cross-linguistic findings suggest that this principle governing belief ascription may well be a universal, although we also find some variation across sites in the size of the minority of people taking behavioral circumscription into account while ascribing belief. Future research could examine whether this principle governing belief ascription is robust, extending to other kinds of delusion cases (e.g., Cotard delusion, paranoid schizophrenia, etc.) and nondelusional cases (e.g., religious belief, implicit racism).

\section{Acknowledgments}

We would like to thank John Turri, Wesley Buckwalter and two anonymous reviewers for helpful comments on earlier versions of this paper. This publication was made possible through the support of a grant from the Fuller Theological Seminary/Thrive Center in concert with the John Templeton Foundation. The opinions expressed in this publication are those of the authors and do not necessarily reflect the views of the Fuller Thrive Center or the John Templeton Foundation.

\section{Notes}

${ }^{1}$ Except in Lebanon where the cases were presented in English.

${ }^{2}$ Throughout, for significant effects, we report effect sizes using Cramer's $V$, which is a nonparametric correlation coefficient that indicates the strength of the relationship between nominal variables. This measure delivers a value between 0 and 1. We follow Ellis (2010) for interpreting the magnitude of the effect sizes. So for Cramer's $V$ we interpret values greater than or equal to .5 as large, greater than or equal to .3 but less than .5 as medium, and greater than or equal to .1 but less than .3 as small.

${ }^{3}$ We informally polled 25 English speaking informants and all of them said it was likely that the speaker in our Capgras cases was sincere. We also asked some research partners who conducted the research in other languages whether they thought speakers of that language would regard the statement by Don in the Capgras cases as sincere. They said it was likely that speakers of these respective languages think that the speaker in our Capgras cases was sincere.

${ }^{4}$ We use small caps to denote concepts. 


\section{References}

Bayne, T. "Delusions as Doxastic States: Contexts, Compartments, and Commitments." Philosophy, Psychiatry, and Psychology 17.4 (2010): 329-336.

Bortolotti, L."In Defense of Modest Doxasticism about Delusions.” Neuroethics 5.1 (2012): 39-53.

Bortolotti, L. and M. Mameli. "Self-Deception, Delusion and the Boundaries of Folk Psychology." Humana Mente 20(2012): 203-221.

Currie, G. Imagination, Delusion and Hallucinations, in Pathologies of Belief, edited by Max Coltheart and Martin Davies. Oxford: Blackwell, 2000.

Currie, G. and J. Jureidini. "Delusion, Rationality, Empathy, Philosophy.” Psychiatry and Psychology 8.2-3 (2001): 159-162.

Currie, G. and I. Ravenscroft. Recreative Minds: Imagination in Philosophy and Psychology. New York: Oxford University Press, 2002.

Egan, A. "Imagination, Delusion, and Self-Deception," in Delusions, Self-Deception, and Affective Influences on Belief Formation, edited by Tim Bayne and Jordi Fernandez. New York: Psychology Press, 2009, 263-279.

Ellis, Paul. The Essential Guide to Effect Sizes: Statistical Power, Meta-Analysis and the Interpretation of Research Results. New York: Cambridge University Press, 2010.

Frankish, K. "Delusions, Levels of Belief, and non-doxastic Acceptances.” Neuroethics 5.1 (2012): 23-27.

Hirstein, W. and V. S. Ramachandran. "Capgras Syndrome: A Novel Probe for Understanding the Neural Representation of the Identity and Familiarity of Persons." Proceedings of the Royal Society of London B264(1997): 437-444.

Murphy, D.“The Folk Epistemology of Delusions.” Neuroethics 5.1 (2012): 19-22.

Reimer, M. "Only a Philosopher or a Madman: Impractical Delusions in Philosophy and Psychiatry." Philosophy, Psychiatry, and Psychology 17.4 (2010): 315-328.

Rose, D., W. Buckwalter, and J. Turri. "When Words Speak Louder than Actions: Delusion, Belief and the Power of Assertion." Australasian Journal of Philosophy 92.4 (2014): 1-18.

Schwitzgebel, E. "In-between Believing.” The Philosophical Quarterly 51.202 (2001): 76-82.

Schwitzgebel, E. "Acting Contrary to Our Professed Beliefs, or the Gulf between Occurrent Judgment and Dispositional Belief." Pacific Philosophical Quarterly 91.4 (2010): 531-553.

Schwitzgebel, E. "Mad Belief?" Neuroethics 5.1 (2012): 13-17.

Tumulty, M. "Delusions and Not-Quite-Beliefs." Neuroethics 5.1 (2012): 29-37.

Wierzbicka, A. English Meaning and Culture. New York: Oxford University Press, 2006. 